\title{
Caffeic acid rich Citrus macroptera peel powder supplementation prevented oxidative stress, fibrosis and hepatic damage in $\mathrm{CCl}_{4}$ treated rats
}

\author{
Md Ashraful Alam ${ }^{1 *+}$, Abu Taher Sagor ${ }^{1 \dagger}$, Nabila Tabassum ${ }^{1}$, Anayt Ulla ${ }^{1}$, Manik Chandra Shill ${ }^{1}$, \\ Ghazi Muhammad Sayedur Rahman ${ }^{1}$, Hemayet Hossain ${ }^{2}$ and Hasan Mahmud Reza ${ }^{1 *}$
}

\begin{abstract}
Background: Citrus macroptera has been used as a culinary fruit and medicinal plant in traditional medicine system in Bangladesh. The aim of the present study was to evaluate the presence of phenolic compounds in Citrus macroptera peel powder and the protective effect of Citrus macroptera against carbon tetrachloride $\left(\mathrm{CCl}_{4}\right)$ induced liver injury in rats.

Methods: The hepatoprotective activity was assessed using various biochemical parameters such as liver marker enzymes (alanine aminotransferase (ALT), aspartate aminotransferase (AST), alkaline phosphatase (ALP)) and oxidative stress parameters. Histopathological changes in the liver of different groups were also studied.

Results: Administration of $\mathrm{CCl}_{4}$ increased the serum ALT, AST, ALP enzymatic activities and lipid peroxidation products but decreased the cellular antioxidant activities and reduced glutathione (GSH) levels in rats which were brought back to near normal levels by the treatment with Citrus macroptera. Citrus macroptera administration has also shown to decrease the necrotic zones, fibrosis and inflammatory cell infiltration in $\mathrm{CCl}_{4}$ treated rats. HPLC-DAD analysis of Citrus macroptera extract showed the great presence of caffeic acid and (-) epicatechin.
\end{abstract}

Conclusion: The results of this study suggest that Citrus macroptera exerts hepatoprotective activity via promoting the antioxidant defense against $\mathrm{CCl}_{4}$-induced oxidative liver damage.

Keywords: Citrus macroptera, Oxidative stress, Fibrosis, Inflammation, Caffeic acid

\section{Background}

Hepatotoxicity is a growing public health concern in modern society due to the increasing incidence of alcoholism, cigarette smoking, drug abuse and other unhealthy lifestyle options such as consuming high fructose-containing beverages and high fat containing foods. Liver damage is characterized by a progressive development of steatosis to chronic hepatitis, fibrosis, cirrhosis, and hepatocellular carcinoma [1,2]. Oxidative stress plays a central role in the development of liver diseases. Carbon tetrachloride

\footnotetext{
*Correspondence: sonaliagun@yahoo.com; ashraful.alam@northsouth.edu; hasan.reza@northsouth.edu

${ }^{\dagger}$ Equal contributors

'Department of Pharmaceutical Sciences, North South University, Dhaka, Bangladesh

Full list of author information is available at the end of the article
}

$\left(\mathrm{CCl}_{4}\right)$ is a widely used solvent in chemical industries and well known for its hepatic and renal toxic actions. It is also used to establish experimental animal model of hepatic dysfunction in the laboratory [3, 4]. The metabolism of $\mathrm{CCl}_{4}$ occurs mainly in the liver by CYP450 enzyme system into trichloromethyl $\left({ }^{\circ} \mathrm{CCl}_{3}\right)$ and peroxy trichloromethyl $\left.\left({ }^{\circ} \mathrm{OOCCl}\right)_{3}\right)$ free radicals which have been reported to cause hepatotoxic effects, like fibrosis, steatosis, necrosis, and hepatocarcinoma [3,5]. Chronic insult to the liver due to hepatotoxins, alcohol consumption and highcalorie diet triggers inflammation and fibrosis [4]. Liver fibrosis is a dynamic process where oxidative stresses are responsible for the activation of hepatic stellate cells (HSCs) [6]. HSCs are the major cell types responsible for the deposition of a large amount of extracellular matrix 
(ECM) and collagen in liver [7]. $\mathrm{CCl}_{4}$-mediated liver fibrosis is characterized by activation of Kupffer cells and induction of an inflammatory response by secreting cytokines, chemokines and other pro-inflammatory factors [8]. $\mathrm{CCl}_{4}$ treatment also attracts more inflammatory cells in liver apart from Kuffer cells and further contributes to liver necrosis [8]. High level of lipid peroxidation products and decreased antioxidant levels were also noted in $\mathrm{CCl}_{4}$ mediated hepatic dysfunction in animal [9]. As oxidative stress plays a central role in liver pathologies and their progression, the use of antioxidants would have been an alternative therapeutic approach to counteract the liver damage. Citrus fruits are a rich source of natural antioxidants and showed beneficial role in various degenerative diseases [10]. Caffeic acid was found in high amount compared to other phenolic compounds in Citrus macroptera peel which is a strong antioxidant compound [11]. Caffeic acid also showed hepatic protection and prevented fibrosis in various experimental animal models [12-14]. This hepatoprotective activity of caffeic acid is linked to improved antioxidant defense and inflammatory state in liver $[11,15]$.

Citrus macroptera is known as 'Satkara' in Bengali and 'Wild orange' in English. It is a semi-wild species of citrus fruits which is native to the regions of Southeast Asia and found in large amount in Sylhet Division of Bangladesh. The fruit is used as a cooking ingredient in different kinds of meats and as an aromatic vegetable in Bangladesh. Meats cooked with satkara are now served in many Bangladeshi/Indian restaurants in the United Kingdom. Citrus macroptera (Satkara) fruit is also used as an appetite stimulant and in the treatment of fever as reported in the traditional system of medicine in Bangladesh. The previous report suggested that Citrus macroptera contains mainly lupeol and stigmasterol [16]. Other studies conducted on the bark and leaves of the Citrus macroptera reported the antioxidant and antimicrobial activities $[16,17]$. A recent investigation also suggests that Citrus macroptera extract showed in-vitro $\alpha$-amylase inhibitory activity and hypoglycemic activity in normal rats [18]. We recently reported the hepatoprotective activity of Citrus maxima peel powder in $\mathrm{CCl}_{4}$ treated rats [19]. However, limited data and few scientific literatures are available on any therapeutic effect of Citrus macroptera in liver diseases. Therefore, this current research was designed to understand the possible anti-inflammatory and anti-fibrotic activity of Citrus macroptera peel powder in hepatic dysfunction in $\mathrm{CCl}_{4}$ treated rats.

\section{Methods}

\section{Chemicals}

Arbutin (AR), gallic acid (GA), hydroquinone (HQ), $(+)$-catechin hydrate $(\mathrm{CH})$, vanillic acid (VA), caffeic acid
(CA), Syringic acid (SA), (-)-epicatechin (EC), vanillin $(\mathrm{VL}), p$-coumaric acid (PCA), trans-ferulic acid (FA), rutin hydrate $(\mathrm{RH})$, ellagic acid (EA), benzoic acid (BA), rosmarinic acid (RA), myricetin (MC), quercetin (QU), trans-cinnamic acid (TCA), and kaempferol (KF) were purchased from Sigma-Aldrich (St. Louis, MO, USA). Acetonitrile (HPLC), methanol (HPLC), acetic acid (HPLC), and ethanol were obtained from Merck (Darmstadt, Germany).

\section{Plant material}

Citrus macroptera fruits were collected from Sylhet, Bangladesh and authenticated by Sarker Nasir Uddin, Senior Scientific Officer, National Herbarium, Mirpur, Dhaka. A voucher specimen (Acc. No. 40847) was deposited in the herbarium for future reference. The peels were removed and dried for further processing. The dried peels were grinded to fine powder using an electric grinder machine and mixed with the food directly as supplementation. A portion of the dried peel powder was used to prepare crude ethanol extract and used for polyphenol detection and quantification.

\section{High performance liquid Chromatograpgy (HPLC) detection and quantification of polyphenolic compounds} Detection and quantification of selected phenolic compounds in the ethanol extract were determined by HPLC-DAD analysis as described by Ismet et al. [20] with some modifications. It was carried out on a Dionex UltiMate 3000 system equipped with quaternary rapid separation pump (LPG-3400RS) and photodiode array detector (DAD-3000RS). Separation was performed using Acclaim ${ }^{\circ} \mathrm{C}_{18}(5 \mu \mathrm{m})$ Dionex column $(4.6 \times$ $250 \mathrm{~mm}$ ) at $30{ }^{\circ} \mathrm{C}$ with a flow rate of $1 \mathrm{ml} / \mathrm{min}$ and an injection volume of $20 \mu \mathrm{l}$. For the preparation of calibration curve, a standard stock solution was prepared in methanol containing arbutin, (-)-epicatechin $(5 \mu \mathrm{g} / \mathrm{ml}$ each), gallic acid, hydroquinone, vanillic acid, rosmarinic acid, myricetin ( $4 \mu \mathrm{g} / \mathrm{ml}$ each), caffeic acid, Syringic acid, vanillin, trans-ferulic acid (3 $\mu \mathrm{g} / \mathrm{ml}$ each), $p$-coumaric acid, quercetin, kaempferol $(2 \mu \mathrm{g} / \mathrm{ml}$ each), (+)-catechin hydrate, ellagic acid $(10 \mu \mathrm{g} / \mathrm{ml}$ each $)$, trans-cinnamic acid $(1 \mu \mathrm{g} / \mathrm{ml})$, rutin hydrate $(6 \mu \mathrm{g} / \mathrm{ml})$ and benzoic acid $(8 \mu \mathrm{g} / \mathrm{ml})$. The UV detector was set to $280 \mathrm{~nm}$ for 22 . $0 \mathrm{~min}$, changed to $320 \mathrm{~nm}$ for $28.0 \mathrm{~min}$, again change to $280 \mathrm{~nm}$ for $35 \mathrm{~min}$ and finally to $380 \mathrm{~nm}$ for $36 \mathrm{~min}$ and held for the rest of the analysis period while the diode array detector was set at an acquisition range from $200 \mathrm{~nm}$ to $700 \mathrm{~nm}$.

\section{Animals and treatment}

Ten to 12 weeks old, 24 Long Evans female rats (150$170 \mathrm{~g})$ were obtained from Animal breeding unit of Animal House at the Department of Pharmaceutical Sciences, North South University and were kept in individual cages 
at room temperature of $25 \pm 3{ }^{\circ} \mathrm{C}$ with a $12 \mathrm{~h}$ dark/light cycles. They had free access to standard laboratory feed and water, according to the study protocol approved by Ethical Committee of Department of Pharmaceutical Sciences, North South University for animal care and experimentation. To evaluate the hepatoprotective effect of Citrus macroptera, rats were equally divided into four groups (six rats in each group). The groups are as follows-

Group I- Animals were treated with $1 \mathrm{ml} / \mathrm{kg}$ of saline $(0.85 \%)$ and olive oil $(1 \mathrm{ml} / \mathrm{kg})$ intragastrically twice a week for 2 weeks

Group II- Animals were treated with $1 \mathrm{ml} / \mathrm{kg}$ of saline $(0.85 \%)$ and olive oil $(1 \mathrm{ml} / \mathrm{kg})$ intragastrically twice a week for 2 weeks. Animals of group II also received Citrus macroptera fruit peel powder supplementation mixed with food $(0.5 \%$ of the diet, $w / \mathrm{w})$.

Group III - Animals were treated with $\mathrm{CCl}_{4}$ (1:3 in olive oil) at a dose of $1 \mathrm{ml} / \mathrm{kg}$ intragastrically twice a week for 2 weeks.

Group IV- Animals were treated with $\mathrm{CCl}_{4}$ (1:3 in olive oil) at a dose of $1 \mathrm{ml} / \mathrm{kg}$ intragastrically twice a week for 2 weeks. Animals of group IV also received Citrus macroptera fruit peel powder mixed in food $(0.5 \%$ of the diet, w/w) respectively, in addition to $\mathrm{CCl}_{4}$. treatment, twice a week for 2 weeks.

Animals of group I were served as control animals. Animals were checked for the body weight, food and water intake on a daily basis. After 14 days, all animals were weighted and sacrificed, collected the blood in citrate buffer containing tubes and all the organs such as heart, kidney, spleen, and liver were havested. Immediately after collection of the organs, they are weighted and one part was stored in neutral buffered formalin ( $\mathrm{pH}$ 7.4) for histological analysis and another part was kept in the refrigerator at $-20{ }^{\circ} \mathrm{C}$ for further studies. The collected blood was centrifuged at $8000 \mathrm{rpm}$ and separated the plasma and stored in a refrigerator at $20{ }^{\circ} \mathrm{C}$ for further analysis.

\section{Assessment of hepatotoxicity}

Liver marker enzymes (alanine aminotransferase (ALT), aspartate aminotransferase (AST), and alkaline phosphatase (ALP) were estimated in plasma by using Diatec diagnostic kits (Hungary) according to the manufacturer's protocol.

\section{Preparation of tissue sample for the assessment of oxidative stress markers}

For determination of oxidative stress markers, $0.2 \mathrm{~g}$ of liver tissue was homogenized in $1.8 \mathrm{~mL}$ Phosphate buffer (pH 7.4) and centrifuged at $10000 \mathrm{rpm}$ for $30 \mathrm{~min}$ at $4{ }^{\circ} \mathrm{C}$.
The supernatant was collected and used for the determination of protein and enzymatic studies as described below.

\section{Estimation of lipid peroxidation}

Lipid peroxidation in liver was estimated colorimetrically measuring thiobarbituric acid reactive substances (TBARS) followed by previously described method [21].

\section{Assay of nitric oxide (NO)}

Nitric oxide (NO) was determined according to the method described by Tracey et al. as nitrate [22]. In this study, Griess-Illosvoy reagent was modified by using naphthyl ethylenediamine dihydrochloride $(0.1 \% \mathrm{w} / \mathrm{v})$ instead of 1-naphthylamine (5\%).

\section{Advanced protein oxidation products (APOP) assay:}

APOP levels were measured by a modification of the method of Witko-Sarsat et al. [23] and Tiwari et al. [24]. APOP concentrations were expressed as $\mathrm{nmol} \cdot \mathrm{mL}^{-1}$ chloramine-T equivalents.

\section{Catalase assay (CAT)}

CAT activities were determined using previously described the method by Chance and Maehly [25]. One unit of CAT activity was defined as an absorbance change of 0.01 as units/min.

\section{Reduced glutathione assay (GSH)}

Reduced glutathione was estimated by the method of Jollow et al. [26]. $1.0 \mathrm{ml}$ sample of $10 \%$ homogenate was precipitated with $1.0 \mathrm{ml}$ of (4\%) sulfosalicylic acid. The samples were kept at $4{ }^{\circ} \mathrm{C}$ for $1 \mathrm{~h}$ and then centrifuged at $4000 \mathrm{rpm}$ for $20 \mathrm{~min}$ at $4{ }^{\circ} \mathrm{C}$. The total volume of 3 . $0 \mathrm{ml}$ assay mixture composed of $0.1 \mathrm{ml}$ filtered aliquot, $2.7 \mathrm{ml}$ phosphate buffer $(0.1 \mathrm{M}, \mathrm{pH} 7.4)$ and $0.2 \mathrm{ml}$ DTNB (5,5-dithiobis-2-nitrobenzoic acid), (100 mM). The mixture which was developed as yellow color, UV absorbance was taken immediately at $412 \mathrm{~nm}$ on a Smart SpecTM plus Spectrophotometer and the content of GSH was expressed as ng/mg protein.

\section{Histopathological determination}

For microscopic evaluation, liver tissues were fixed in neutral buffered formalin and embedded in paraffin, sectioned at $5 \mu \mathrm{m}$ and subsequently stained with hematoxylin/eosin to see the architecture of hepatic tissue and inflammatory cell infiltration. Liver injury score in the Hematoxylin/ eosin stained sections were evaluated as follows: 0, minimal or no evidence of injury; 1, mild injury consisting of cytoplasmic vacuolation and focal nuclear pyknosis; 2, moderate to severe injury with extensive nuclear pyknosis and loss of intercellular borders and 3, severe necrosis with disintegration of hepatic cords, hemorrhage and 
neutrophil infiltration. All evaluations were made in 3 fields per section and 3 sections per liver.

Sirius red staining for fibrosis and Prussian blue staining for iron deposition were also done in liver sections. Sections were then studied and photographed under a light microscope (Zeiss Axioscope) at 40 magnifications. Collagen deposition was semiquantitatively measured using NIH Image J free software (Version 1.48v).

\section{Statistical analysis}

All values are expressed as a mean \pm standard error of the mean (SEM). The results were evaluated by using the One-way ANOVA followed by Bonferroni test using Graph Pad Prism Software, version 6. Statistical significance was considered $p<0.05$ in all cases.

\section{Results}

\section{Effect on body weight, food, and water intake}

Body weight of each rat was recorded every day during the experiment, and \% change was calculated for all groups. It was found that the body weight decreased significantly in $\mathrm{CCl}_{4}$-intoxicated rat group, which is a typical feature of chronic liver intoxication. On the other hand, treatment of $\mathrm{CCl}_{4}$ treated group with Citrus macroptera markedly improved the weight loss of rats (Table 1). $\mathrm{CCl}_{4}$ treated rats group showed significant decrease in food, and water intake compared to control rats. Reduction of food and water intake in $\mathrm{CCl}_{4}$ treated rats group was further improved in Citrus macroptera treated group (Table 1).

\section{Effect on organ wet weight}

Table 1 shows the effect of various treatments on the rats' organs weight. The spleen wet weight was significantly $(p=0.012)$ increased in the $\mathrm{CCl}_{4}$-treated rats compared to control rats. Citrus macroptera ( $0.5 \%$ per $\mathrm{kg}$ of diet) treatment did not significantly attenuate the wet weight of the spleen in the $\mathrm{CCl}_{4}$-treated rats. $\mathrm{CCl}_{4}$ - treated rats also showed decreased in liver wet weight; however, Citrus macroptera supplementation did not change the wet weight of the liver compared to the control. Another crucial finding in this study was the reduction of kidney wet weight due to $\mathrm{CCl}_{4}$ intoxication which was normalized by Citrus macroptera supplementation (Table 1). Wet weights of the heart were relatively unchanged among the groups tested in this study (Table 1).

\section{Effect on biochemical parameter of liver functions}

Biochemical assay of liver function markers revealed that $\mathrm{CCl}_{4}$ administration in rats induced a significant $(p<0.05)$ increase in plasma AST $(p=0.036)$, ALT $(p<0.0001)$, and ALP $(p<0.0001)$ activity compared to control rats, respectively (Table 2$)$. Citrus macroptera ( $0.5 \%$ of diet) supplementation concurrently with $\mathrm{CCl}_{4}$ significantly $(p<0$. 05) counteracted the alteration in all hepatotoxicity indices compared to the $\mathrm{CCl}_{4}$-treated group. In addition, supplementation with Citrus macroptera alone in the diet for 2 weeks in normal control rats did not show any significant change in liver enzymes compared to the control rats (Table 2).

\section{Oxidative stress markers and antioxidant enzymes}

To determine the oxidative stress in our study, we evaluated the MDA, nitric oxide and APOP concentration in plasma and liver homogenates. $\mathrm{CCl}_{4}$ administration in rats showed an increased lipid peroxidation product, MDA concentration both in plasma $(p<0.0001)$ and in liver $(p=0.0004)$ homogenates significantly $(p<0.05)$ (Table 2). Additionally, Citrus macroptera (0.5\% of diet) supplementation significantly $(\mathrm{p}<0.05)$ reduced the level of lipid peroxides compared to $\mathrm{CCl}_{4}$ intoxicated group.

$\mathrm{CCl}_{4}$ administration in rats also increased APOP development in plasma and in liver compared to control rats significantly $(p<0.0001)$. Citrus macroptera $(0.5 \%$ of diet $)$ supplementation in $\mathrm{CCl}_{4}$ intoxicated rats significantly $(p<$

Table 1 Effect of Citrus macroptera peel powder supplementation on body weight, food and water intake and organ weight of $\mathrm{CCl}_{4}$ treated rats

\begin{tabular}{lllll}
\hline Parameters & Control & Control+Citrus macroptera & $\mathrm{CCl}_{4}$ & CCl $_{4}+$ Citrus macroptera \\
\hline Initial Bodyweight $(\mathrm{g})$ & $156.07 \pm 2.38$ & $165.63 \pm 2.99 \mathrm{~ns}$ & $162.92 \pm 4.81 \mathrm{nss}$ & $162.67 \pm 1.52 \mathrm{~ns}$ \\
Final Bodyweight $(\mathrm{g})$ & $167.37 \pm 4.05$ & $182.40 \pm 5.95 \mathrm{~ns}$ & $165.92 \pm 5.23 \mathrm{~ns}$ & $174.20 \pm 3.16 \mathrm{~ns}$ \\
Food intake/d (g/day) & $16.49 \pm 0.88$ & $15.68 \pm 0.97 \mathrm{a}$ & $12.21 \pm 0.54 \mathrm{a}$ & $15.03 \pm 0.57 \mathrm{~b}$ \\
Water intake/d (ml/day) & $18.85 \pm 0.62$ & $20.11 \pm 1.20 \mathrm{~ns}$ & $13.44 \pm 0.73 \mathrm{a}$ & $15.20 \pm 0.78 \mathrm{~b}$ \\
Liver wet weight (g/100 g of body weight) & $3.67 \pm 0.15$ & $3.68 \pm 0.06 \mathrm{~ns}$ & $3.32 \pm 0.09 \mathrm{~ns}$ & $3.47 \pm 0.05 \mathrm{~ns}$ \\
Kidneys wet weight (g/100 g of body weight) & $0.62 \pm 0.02$ & $0.56 \pm 0.04 \mathrm{~ns}$ & $0.53 \pm 0.02 \mathrm{a}$ & $0.62 \pm 0.01 \mathrm{~b}$ \\
Heart wet weight (g/100 g of body weight) & $0.34 \pm 0.01$ & $0.28 \pm 0.00$ & $0.31 \pm 0.02$ & $0.30 \pm 0.01$ \\
Spleen wet weight (g/100 g of body weight) & $0.31 \pm 0.03$ & $0.39 \pm 0.02 \mathrm{~ns}$ & $0.46 \pm 0.04 \mathrm{a}$ & $0.41 \pm 0.02 \mathrm{~ns}$ \\
\hline
\end{tabular}

Values are presented as mean \pm SEM. $N=6$ in each group or otherwise specified. One way ANOVA with Bonferoni tests were done as post hoc test. Values are considered significance at $p<0.05$. control vs $\mathrm{CCl}_{4}$ significanltly different at $\mathrm{a}<0.05$. $\mathrm{CCl}_{4}$ vs Citrus macroptera treatment which are significantly different at $\mathrm{b}<$ 0.05. ns- non significant 
Table 2 Effect of Citrus macroptera peel powder supplementation on biochemical parameters in plasma and liver of $\mathrm{CCl}_{4}$ treated rats

\begin{tabular}{|c|c|c|c|c|}
\hline \multirow[t]{2}{*}{ Parameters } & \multicolumn{4}{|l|}{ Groups } \\
\hline & Control & Control+Citrus macroptera & $\mathrm{CCl}_{4}$ & $\mathrm{CCl}_{4}+$ Citrus macroptera \\
\hline \multicolumn{5}{|l|}{ Plasma } \\
\hline AST(U/L) & $34.45 \pm 3.85$ & $35.89 \pm 3.46 \mathrm{~ns}$ & $65.46 \pm 8.87 a$ & $47.37 \pm 4.85 b$ \\
\hline $\mathrm{ALT}(\mathrm{U} / \mathrm{L})$ & $30.15 \pm 2.94$ & $31.58 \pm 2.87 \mathrm{~ns}$ & $66.04 \pm 2.87 a$ & $43.07 \pm 5.88 b$ \\
\hline$A L P(U / L)$ & $57.60 \pm 1.38$ & $33.76 \pm 4.95 b$ & $80.35 \pm 5.58 a$ & $37.57 \pm 7.21 b$ \\
\hline $\mathrm{MDA}(\mathrm{nmol} / \mathrm{mL})$ & $7.27 \pm 0.19$ & $11.01 \pm 0.47 \mathrm{~ns}$ & $17.27 \pm 1.79 a$ & $9.81 \pm 0.42 b$ \\
\hline $\mathrm{NO}(\mathrm{nmol} / \mathrm{mL})$ & $3.87 \pm 0.27$ & $4.43 \pm 0.70 \mathrm{~ns}$ & $6.80 \pm 0.65 a$ & $3.42 \pm 0.61 b$ \\
\hline APOP (nmol/mL equivalent to Chloramine-T) & $228.33 \pm 10.66$ & $326.35 \pm 56.23 \mathrm{~ns}$ & $736.27 \pm 54.83 a$ & $347.38 \pm 26.18 b$ \\
\hline GSH (ng/mg protein) & $11.85 \pm 0.51$ & $11.25 \pm 0.74 \mathrm{~ns}$ & $7.50 \pm 0.40 a$ & $13.63 \pm 1.22 b$ \\
\hline Catalase (U/min) & $7.17 \pm 0.79$ & $10.50 \pm 1.20 \mathrm{~ns}$ & $5.33 \pm 1.05 \mathrm{~ns}$ & $7.00 \pm 1.06 \mathrm{~ns}$ \\
\hline \multicolumn{5}{|l|}{ Liver } \\
\hline $\mathrm{NO}(\mathrm{nmol} / \mathrm{mL})$ & $14.12 \pm 0.91$ & $12.35 \pm 0.92 \mathrm{~ns}$ & $15.87 \pm 2.23 \mathrm{~ns}$ & $12.47 \pm 1.20 \mathrm{~ns}$ \\
\hline $\mathrm{MDA}(\mathrm{nmol} / \mathrm{mL})$ & $38.77 \pm 1.84$ & $40.31 \pm 2.02 \mathrm{~ns}$ & $64.41 \pm 4.89 \mathrm{ba}$ & $51.33 \pm 5.13 \mathrm{~ns}$ \\
\hline APOP (nmol/mL equivalent to Chloramine-T) & $632.06 \pm 33.84$ & $497.78 \pm 29.20 \mathrm{~ns}$ & $968.57 \pm 70.27 a$ & $566.43 \pm 48.60 b$ \\
\hline Catalase (U/min) & $20.83 \pm 3.52$ & $24.17 \pm 3.00 \mathrm{~ns}$ & $14.17 \pm 2.01 a$ & $23.33 \pm 2.47 b$ \\
\hline
\end{tabular}

Values are presented as mean \pm SEM. $\mathrm{N}=6$ in each group or otherwise specified. One way ANOVA with Bonferroni tests were done as post hoc test. Values are considered significant at $p<0.05$. Values are considered significance at $p<0.05$. control vs $\mathrm{CCl}_{4}$ significanltly different a $<0.05$. CCl 4 vs Citrus macroptera treatment which are significantly different at $\mathrm{b}<0.05$. ns- non significant. APOP-Advanced protein oxidation product expressed as $\mathrm{nmol} / \mathrm{mL}$ equivalent to $\mathrm{Chloramine-T}$

0.05) reduced the APOP concentration in plasma and liver tissue homogenates significantly (Table 2).

NO measured as nitrate was also increased significantly $(p=0.0027)$ in plasma of $\mathrm{CCl}_{4}$ administered rats compared to control rats (Table 2). Citrus macroptera (0.5\% of diet) supplementation (Table 2) in $\mathrm{CCl}_{4}$ administered rats normalized the elevated the NO level in plasma. However, NO level was not changed significantly in liver homogenates of $\mathrm{CCl}_{4}$ administered rats compared to control rats. This effect could be attributed to the rapid excretion of nitrate into the plasma from liver tissues.

$\mathrm{CCl}_{4}$ administration also decreased plasma antioxidant such as GSH concentration $(p=0.0002)$ compared to the control rats (Table 2). Citrus macroptera (0.5\% of diet) supplementation in $\mathrm{CCl}_{4}$ administered rat significantly counteracted the oxidative stress by restoring the antioxidant GSH concentration compared to the $\mathrm{CCl}_{4}$ administered rats (Table 2). Moreover, catalase activity was decreased in $\mathrm{CCl}_{4}$ administered rats compared to control rats. However, the changes were not statistically significant. Citrus macroptera ( $0.5 \%$ of diet) supplementation in $\mathrm{CCl}_{4}$ administered rat increased the catalase activity compared to the $\mathrm{CCl}_{4}$ administered rats (Table 2). Citrus macroptera $(0.5 \%$ of diet) supplementation in control rats did not alter the catalase activity compared to control rats (Table 2).

\section{Inflammation, fibrosis iron deposition in liver}

Figure 1a showed the well-formed hepatocytes in an intact hepatic lobule of normal rat liver. However, inflammation was seen in rats treated with $\mathrm{CCl}_{4}$. A massive surge of inflammatory cells was found in the centrilobular part of liver sections stained Researchers are still working on natural plants to discover new compounds of high biological activitystaining in $\mathrm{CCl}_{4}$ treated rats group (Fig. 1c). Necrotized tissue scar in liver was also seen in the liver of $\mathrm{CCl}_{4}$ treated rats (Fig. 1c). Citrus macroptera (0.5\% of diet) supplementation attenuated the inflammatory cell infiltration and necrosis in the liver tissues of $\mathrm{CCl}_{4}$ treated rats (Fig. 1d). Liver fibrosis was evaluated histologically by visualizing the red color of collagen fibers using Sirius red stain. No collagen deposition was observed in control rats (Fig. 2a). Collagen fibers were heavily deposited around portal tracts and central veins in $\mathrm{CCl}_{4}$-intoxicated rat's liver and extended from central vein to portal tract resulting in the formation of pseudolobules (Fig. 2c). Citrus macroptera $(0.5 \%$ of diet) supplementation prevented the deposition of collagen fibers in the liver of $\mathrm{CCl}_{4}$ treated rats (Fig. 2d).

Histological staining also revealed that no free iron was deposited in the liver of control rats (Fig. 3a) whereas high amount iron deposition was found in liver section stained for the free iron depot in $\mathrm{CCl}_{4}$ treated rats (Fig. 3c). Citrus macroptera supplementation decreased iron deposition in $\mathrm{CCl}_{4}$ treated rats (Fig. 3d).

\section{Analysis of ethanol extract of Citrus macroptera by HPLC- DAD}

Identification and quantification of individual phenolic compounds in the ethanol extract of Citrus macroptera 


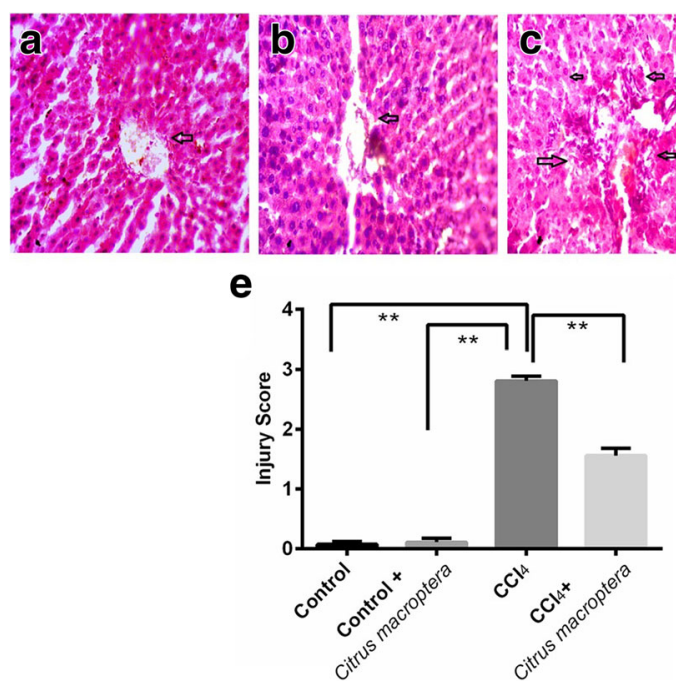

Fig. 1 Effect of Citrus macroptera peel powder on hepatic inflammation in $\mathrm{CCl}_{4}$ treated rats. a, Control, showed normal architecture of hepatocyte with no nuclear pyknosis; $\mathbf{b}$, Control + C macroptera, showed normal architecture of hepatocyte with no nuclear pyknosis; $\mathbf{c} \mathrm{CCl}_{4}$, showed severe

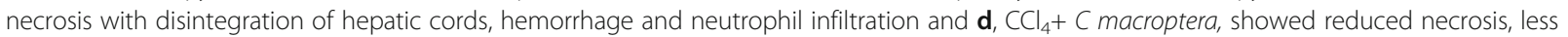
hemorrhage and minimized neutrophil infiltration. Magnification 40x. ic-inflammatory cells. e, shows the injury scores in different experimental groups after $\mathrm{CCl}_{4}$ chalenge and treatment

were analyzed by HPLC-DAD. The chromatographic separations of polyphenols in ethanol extract are shown in Fig. 4. The content of each phenolic compound was calculated from the corresponding calibration curve and presented as the mean of five determinations as shown in Table 3. Caffeic acid was detected as the most abundant phenolic compound $(428.36 \mathrm{mg} / 100 \mathrm{~g}$ of dry extract) found in the ethanol extract.

\section{Discussion}

Currently, public awareness program against liver diseases such as fibrosis and cirrhosis are being aggressively focused [27]. The liver is the main organ where almost all kinds of toxins, foods as well as drugs are detoxified [28]. $\mathrm{CCl}_{4}$ is metabolized in phase-I reaction and activates the ROS producing system [29]. In the current study, $\mathrm{CCl}_{4}$ administration in rats developed hepatic damage by increasing lipid peroxidation and oxidative stress. $\mathrm{CCl}_{4}$ administration in rats also increased inflammatory cells infiltration and fibrosis in liver tissues. Our investigation also suggests that Citrus macroptera peel powder supplementation ameliorated most of the deleterious effects developed in $\mathrm{CCl}_{4}$ administered rats.

The active metabolite of $\mathrm{CCl}_{4}$ lead to hepatocyte damage and may initiate the leakage of a lot of hepatic enzymes (AST, ALT, and ALP) in blood circulation which was associated with immune cells infiltration, massive centrilobular apoptosis, ballooning degeneration and finally cell death [30]. Elevated liver marker enzymes activities (AST, ALP, and ALT) indicate the dysfunction and damage in the liver during disease condition [31]. This study also revealed the increased liver marker enzymes (AST, ALP, and ALT) activities in $\mathrm{CCl}_{4}$ administered rats which were decreased or normalized by Citrus macroptera supplementation. The previous study reported that reduction of liver enzyme activity would be beneficial in case of hepatic damage protection [32]. Earlier investigations also showed that derivative of
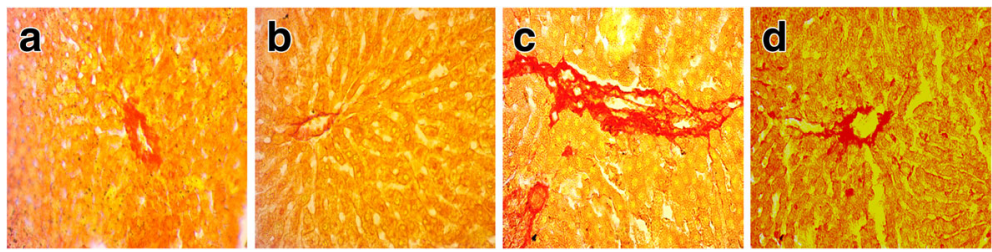

Fig. 2 Effect of Citrus macroptera peel powder on hepatic fibrosis in $\mathrm{CCl}_{4}$ treated rats. a, Control, showed baseline collagen around the hepatic duct, no fibrosis developed; $\mathbf{b}$, Control + C macroptera, showed baseline collgen around the hepatic duct, no fibrosis developed; $\mathbf{c}$, $\mathrm{CCl}_{4}$, Collagen deposition and fibrosis occured around the central vein and hepatic duct. $\mathbf{d}, \mathrm{CCl}_{4}+\mathrm{C}_{\text {macroptera, }}$ Collagen deposition was reduced significantly around the central vein and bile duct. Magnification 40x. fb- fibrosis 

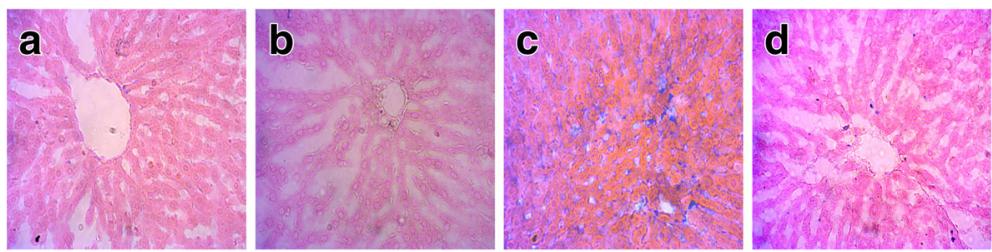

Fig. 3 Effect of Citrus macroptera peel powder on hepatic iron deposition in $\mathrm{CCl}_{4}$ treated rats. a, Control, showed no free iron deposition as seen as blue color stain; $\mathbf{b}$, Control + C macroptera, showed no free iron deposition as seen as blue color stain; $\mathbf{c}$, $\mathrm{CCl}_{4}$, showed free iron deposition as seen as blue color stain and $\mathbf{d}, \mathrm{CCl}_{4}+\mathrm{C}$ macroptera. Magnification $40 \times$

caffeic acid also prevented the liver damage and decreased the liver marker enzymes activities [33, 34].

One of the major markers of hepatic damage is oxidative stress-mediated lipid peroxidation which plays irreversible damage to hepatocellular components. MDA is the outcome of lipid peroxidation in cell membranes and damages the integrity of cells. MDA development also causes an imbalance to lysosomes and helps to oxidize the protein [35]. Our study showed that Citrus macroptera supplementation decreased lipid peroxidation level in plasma and liver tissue compared to $\mathrm{CCl}_{4}$ administered rats. The strong antioxidant can scavenge the free radical and superoxide anions from a biological system. Caffeic acid is a strong antioxidant showed protection against free radical-mediated lipid peroxidation in experimental animals reported previously [34].

Previous studies also reported that anti-oxidant system can reduce inflammatory, pro-inflammatory signaling by inhibiting inducible nitric oxide synthase (iNOS) which is a key factor for immunity responder [36, 37]. iNOS is considered as the major source of $\mathrm{NO}$ in stress condition and generates nitrosative stress. $\mathrm{NO}$ is a vasodilator which maintains regular vascular tone in blood vessels. It also works as a signaling molecule to produce immunological substances when the body needed [38]. However, increased production of $\mathrm{NO}$ in oxidative stress may turn into peroxynitrite (-ONOO•) radical formation which further initiate nitrosative stress in tissues. In this study, we found that $\mathrm{CCl}_{4}$ increased the level of $\mathrm{NO}$ in plasma but not in tissue, which was normalized by the supplementation of Citrus macroptera peel powder. These findings are also supported by a recent investigation, suggested that derivative of caffeic acid prevents NO production in liver [39].

Furthermore, free radicals-mediated oxidative stress also reduces the amount of natural anti-oxidant like SOD, catalase, and GSH which fights against any free radicalsmediated damage in tissues. It is well reported that superoxide radicals $\left(\mathrm{O}_{2}{ }^{\circ}\right)$ are removed by SOD which produces hydrogen peroxide $\left(\mathrm{H}_{2} \mathrm{O}_{2}\right)$ [40]. $\mathrm{H}_{2} \mathrm{O}_{2}$ then further converted into water by another antioxidant enzyme known as catalase [40]. Moreover, $\mathrm{CCl}_{4}$ administration also depleted intracellular-reduced GSH levels, suggesting that GSH loss might result from detoxification of $\mathrm{CCl}_{4}$ by GSH conjugation [40]. GSH also breaks $\mathrm{H}_{2} \mathrm{O}_{2}, \mathrm{ROOH}$ and helps against protein oxidation [41]. Our study revealed that administration of oral $\mathrm{CCl}_{4}$ reduced the amount of anti-

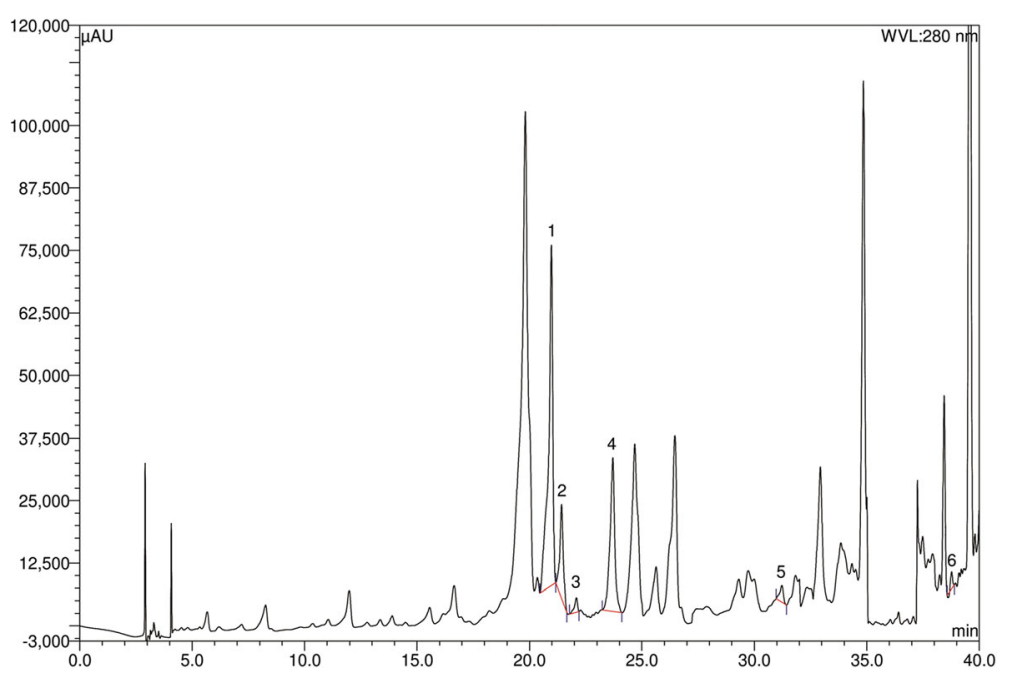

Fig. 4 HPLC chromatogram of Citrus macroptera. Peaks: 1, caffeic acid; 2, syringic acid; 3, (-)-epicatechin; 4, vanillin; 5, benzoic acid; 6, kaempferol 
Table 3 Contents of polyphenolic compounds in the ethanol extract of Citrus $(n=5)$

\begin{tabular}{lll}
\hline $\begin{array}{lll}\text { Polyphenolic } \\
\text { compound }\end{array}$ & Ethanol extract of Citrus macroptera \\
\cline { 2 - 3 } & Content $(\mathrm{mg} / 100 \mathrm{~g}$ of dry extract) & \% RSD \\
\hline Caffeic Acid & 428.36 & 1.91 \\
Syringic Acid & 81.91 & 0.53 \\
(-)-epicatechin & 33.87 & 0.16 \\
vanillin & 52.46 & 0.27 \\
benzoic acid & 47.84 & 0.36 \\
kaempferol & 2.12 & 0.03 \\
\hline
\end{tabular}

oxidant capacity in both plasma and liver tissue which was restored by Citrus macroptera supplementation. Our previous study also demonstrated that iron overload could lead to cause hepatic damage. Free iron in tissues may start Fenton like reaction resulted in a hydroxyl free radicals generation [42]. Supplementation with Citrus macroptera peel powder supplementation reduced iron deposition in the liver of $\mathrm{CCl}_{4}$ treated rats.

The most noteworthy pathological characteristics of $\mathrm{CCl}_{4}$ intoxicated hepatotoxicity are inflammation and fibrosis. Hepatic fibrosis is usually initiated by hepatocyte damage, leading to the recruitment of inflammatory cells and platelets with the subsequent release of cytokines, chemokines, and growth factors [7]. Inflammatory cells infiltration further lead to activation of HSCs and their transformation into myofibroblast-like cells [43]. Chronically activated HSCs produce large amounts of ECM proteins and enhance fibrosis followed by TGF- $\beta 1$ mediated signaling pathways [1]. Free radicals may also activate $\mathrm{HSC}$ which further help to secret collagenase-1 from local fibroblast [1, 44]. Our investigation showed that $\mathrm{CCl}_{4}$ administration significantly enhanced inflammatory cell infiltration and fibrosis in the liver of rats. These findings are in agreement with previously published literature which showed that $\mathrm{CCl}_{4}$ mediated oxidative stress is responsible for the inflammation and fibrosis in liver $[45,46]$. Moreover, Citrus macroptera peel powder supplementation reduced inflammatory cells infiltration and fibrosis in the liver of $\mathrm{CCl}_{4}$ treated rats. This antifibrotic activity of Citrus macroptera peel powder could be attributed to the presence of the antioxidant and anti-inflammatory compound, caffeic acid. Recent findings also suggested that caffeic acid administration in experimental animals may prevent hepatic fibrosis [14, 39].

Researchers are still working on natural plants to discover new compounds of high biological activity. It is reported by World Health Organization (WHO) that more than $80 \%$ people in developing countries basically depends on herbal medicines [47]. Researchers are more focusing on plant-derived polyphenols, seeing that the synthetic anti-oxidants have several adverse effects [48]. Our investigation showed that caffeic acid; syringic acid and vanillic acid are present in Citrus macroptera peel powder. The previous report also suggests that syringic acid and vanillic acid which are important polyphenols showed anti-oxidants, antiinflammatory, anti-fibrogenic and hepatoprotective activities in $\mathrm{CCl}_{4}$ induced rats [49]. Citrus macroptera or wild orange is occasionally used for increasing appetite, reducing fever and making meat preparation [50]. A recent investigation also suggests that Citrus macroptera is extremely safe, even methanolic extract at a dose of $1000 \mathrm{mg} / \mathrm{kg}$ did not produce toxic effects in rats considering biochemical as well as histological assessment [51]. Our investigation also supports this notions that Citrus macroptera peel powder supplementation in normal rats did not alter any of the biochemical as well as histological parameters compared to control rats.

\section{Conclusion}

The current study showed that Citrus macroptera peel powder possesses a good number of polyphenols such as vanillic acid, caffeic acid and syringic acid and benzoic acid. This study also pointed out that oxidative stress can be reduced by Citrus macroptera peel powder supplementation in $\mathrm{CCl}_{4}$ treated rats. Citrus macroptera peel powder was able to reduce iron deposition, inflammation and fibrosis in the liver of $\mathrm{CCl}_{4}$ treated rats. Further studies are required to assess efficacy in the clinical condition of liver damage.

\section{Abbreviations}

ALP: Alkaline phosphatase; ALT: Alanine aminotransferase; APOP: Advanced protein oxidation product; AST: Aspartate aminotransferase; CAT: Catalase;

$\mathrm{CCl}_{3}$ : Trichloromethyl free radical; $\mathrm{CCl}_{3} \mathrm{O}_{2}$ : Trichloroperoxyl radical; $\mathrm{CCl}_{4}$ : Carbon tetrachloride; DTNB: 5,5-dithiobis-2-nitrobenzoic acid; ECM: Extracellular matrix; GSH: Reduced glutathione; $\mathrm{H}_{2} \mathrm{O}_{2}$ : Hydrogen peroxide; HPLC-DAD: High performance liquid choromatography diod array ditector; HSCs: Hepatic stellate cells; iNOS: Inducible nitric oxide synthase; MDA: Malondialdehyde; MPO: Myeloperoxidase; NO: Nitric oxide;

ONOO: Peroxynitrate; ROS: Reactive oxygen species; SOD: superoxide dismutase; TBA: Thiobarbituric acid; TCA: Trichloroacetic acid; TGF-

$\beta$ : Transforming growth factor- $\beta$; TNF-a: Tumor necrosis factor-alpha

\section{Acknowledgements}

Research was conducted in Department of Pharmaceutical Sciences, North South University, Bangladesh. The authors gratefully acknowledge the logistic support provided by the Department of Pharmaceutical Sciences, North South University Bangladesh.

\section{Funding}

This research received no specific grant from any funding agency in the public, commercial, or not-for-profit sectors.

Availability of data and materials

Data generated in this study did not store in any public repositories but will be available upon request which is preserved in our lab computer hard disc. 


\section{Authors' contributions}

MAA, MATS, and HMR designed the experimental design. MATS and NT carried out the animal care, treatment and data acquisition from the experiment. MAA, MATS, and NT performed all the biochemical analysis. MAA, MATS, and AU also performed the histological staining and analysis of tissues. MHH analyzed the extract for phenolic contents through HPLC-DAD system. MAA, AU, GMR and HMR took part in data analysis and manuscript writing. MAA, GMR and HMR checked and finalized the manuscript for submission. The contribution of MCS should be incorporated. All authors read and approved the final manuscript.

\section{Ethics approval}

The study protocol approved by Ethical Committee of Department of Pharmaceutical Sciences, North South University for animal care and experimentation.

\section{Consent for publication}

The authors declare that there is no conflict of interests regarding the publication of this paper.

\section{Author details}

'Department of Pharmaceutical Sciences, North South University, Dhaka, Bangladesh. ${ }^{2}$ BCSIR Laboratories, Bangladesh Council of Scientific and Industrial Research (BCSIR), Dhaka, Bangladesh

\section{Received: 27 November 2017 Accepted: 28 March 2018}

\section{Published online: 10 April 2018}

\section{References}

1. Lee UE, Friedman SL. Mechanisms of hepatic fibrogenesis. Best Pract Res Clin Gastroenterol. 2011;25(2):195-206.

2. Novo E, Parola M. The role of redox mechanisms in hepatic chronic wound healing and fibrogenesis. Fibrogenesis Tissue Repair. 2012;5:1.

3. Constandinou C, Henderson N, Iredale JP. Modeling liver fibrosis in rodents. Methods Mol Med. 2005:117:237-50.

4. Liedtke C, Luedde T, Sauerbruch T, Scholten D, Streetz K, Tacke F, et al. Experimental liver fibrosis research: update on animal models, legal issues and translational aspects. Fibrogenesis Tissue Repair. 2013;6(1):19.

5. Weber LW, Boll M, Stampfl A. Hepatotoxicity and mechanism of action of haloalkanes: carbon tetrachloride as a toxicological model. Critical. Rev Toxicol. 2003;33(2):105-36.

6. Elpek GO. Cellular and molecular mechanisms in the pathogenesis of liver fibrosis: an update. World J Gastroenterol. 2014;20(23):7260-76.

7. Friedman SL. Liver fibrosis - from bench to bedside. J Hepatol. 2003. 38(Suppl 1):S38-53.

8. Luster MI, Simeonova PP, Gallucci RM, Matheson JM, Yucesoy B. Immunotoxicology: role of inflammation in chemical-induced hepatotoxicity. Int J Immunopharmacol. 2000:22(12):1143-7.

9. Yang J, Li Y, Wang F, Wu C. Hepatoprotective effects of apple polyphenols on CCl4-induced acute liver damage in mice. J Agric Food Chem. 2010; 58(10):6525-31.

10. Alam MA, Subhan N, Rahman MM, Uddin SJ, Reza HM, Sarker SD. Effect of citrus flavonoids, naringin and naringenin, on metabolic syndrome and their mechanisms of action. Adv Nutr. 2014;5(4):404-17.

11. Tsai T-H, Yu C-H, Chang Y-P, Lin Y-T, Huang C-J, Kuo Y-H, et al. Protective effect of caffeic acid derivatives on tert-butyl hydroperoxide-induced oxidative hepato-toxicity and mitochondrial dysfunction in HepG2 cells. Molecules 2017;22(5):702.

12. Bocco BM, Fernandes GW, Lorena FB, Cysneiros RM, Christoffolete MA, Grecco SS, et al. Combined treatment with caffeic and ferulic acid from Baccharis uncinella C. DC. (Asteraceae) protects against metabolic syndrome in mice. Braz J Med Biol Res 2016;49.

13. Pari L, Karthikesan K. Protective role of caffeic acid against alcohol-induced biochemical changes in rats. Fundam Clin Pharmacol. 2007;21(4):355-61.

14. Li M, Wang X-F, Shi J-J, Li Y-P, Yang N, Zhai S, et al. Caffeic acid phenethyl ester inhibits liver fibrosis in rats. World J Gastroenterol. 2015;21(13):3893-903.

15. Zhao WX, Wang L, Yang JL, Li LZ, Xu WM, Li T. Caffeic acid phenethyl este attenuates pro-inflammatory and fibrogenic phenotypes of LPS-stimulated hepatic stellate cells through the inhibition of NF-kappaB signaling. Int J Mol Med. 2014;33(3):687-94.
16. Chowdhury SAHS, Datta BK, Choudhury MH. Chemical and antioxidant studies of Citrus macroptera. Bangladesh J Sci Ind Res. 2008:43(4):449-54.

17. Waikedre J, Dugay A, Barrachina I, Herrenknecht C, Cabalion P, Fournet A. Chemical composition and antimicrobial activity of the essential oils from new Caledonian Citrus macroptera and Citrus hystrix. Chem Biodivers. 2010; 7(4):871-7.

18. Uddin N, Hasan MR, Hossain MM, Sarker A, Hasan AHMN, Islam AFMM, et al. In vitro a-amylase inhibitory activity and in vivo hypoglycemic effect of methanol extract of Citrus macroptera. Montr. Fruit. Asian Pac J Trop Biomed. 2014;4(6):473-9.

19. Chowdhury MRH, Sagor MAT, Tabassum N, Potol MA, Hossain H, Alam MA. Supplementation of Citrus maxima peel powder prevented oxidative stress, fibrosis, and hepatic damage in carbon tetrachloride $\left(\mathrm{CCl}_{4}\right)$ treated rats. Evid Based Complement Alternat Med. 2015;2015:10

20. Jahan I, Akbar P, Khan N, Khan T, Rahman M, Arpona H, et al. Comparative study of anti-nociceptive activity and phenolic content of the ethanol extracts of Piper nigrum and Piper longum fruits. Int J Pharm Sci Rev Res. 2014;27:47-52.

21. Niehaus WG, Samuelsson B. Formation of malonaldehyde from phospholipid arachidonate during microsomal lipid peroxidation. Eur J Biochem. 1968;6(1): $126-30$

22. Tracey WR, Tse J, Carter G. Lipopolysaccharide-induced changes in plasma nitrite and nitrate concentrations in rats and mice: pharmacological evaluation of nitric oxide synthase inhibitors. J Pharmacol Exp Ther. 1995; 272(3):1011-5.

23. Witko-Sarsat V, Friedlander M, Capeillère-Blandin C, Nguyen-Khoa T, Nguyen A, Zingraff J, et al. Advanced oxidation protein products as a novel marker of oxidative stress in uremia. Kidney Int. 1996:49:1304-13.

24. Tiwari BK, Kumar D, Abidi AB, Rizvi SI. Efficacy of composite extract from leaves and fruits of medicinal plants used in traditional diabetic therapy against oxidative stress in Alloxan-induced diabetic rats. ISRN Pharmacol. 2014;2014:7

25. Khan RA. Protective effects of Sonchus asper (L.) hill, (Asteraceae) against CCl4-induced oxidative stress in the thyroid tissue of rats. BMC Complement Altern Med. 2012;12(1):181

26. Jollow D, Mitchell J, Zampaglione N, Gillette J. Bromobenzene-induced liver necrosis. Protective role of glutathione and evidence for 3,4-bromobenzene oxide as the hepatotoxic metabolite. Pharmacology. 1974;11:151-69.

27. Heron M. Deaths: leading causes for 2009. Natl Vital Stat Rep. 2012;61(7):1-94.

28. Singh BN, Singh BR, Singh RL, Prakash D, Sarma BK, Singh HB. Antioxidant and anti-quorum sensing activities of green pod of Acacia nilotica L. Food Chem Toxicol. 2009:47(4):778-86.

29. Singh $P$, Singh $U$, Shukla M, Singh $R$. Antioxidant activity imparting biomolecules in Cassia fistula. Adv Life Sci 2008a. 2008;2:23-8.

30. Gowri Shankar NL, Manavalan R, Venkappayya D, David Raj C. Hepatoprotective and antioxidant effects of Commiphora berry (Arn) Engl bark extract against $\mathrm{CCl}_{4}$-induced oxidative damage in rats. Food Chem Toxicol. 2008;46(9):3182-5.

31. Bolanle JD, Adetoro KO, Balarabe SA, Adeyemi OO. Hepatocurative potential of Vitex doniana root bark, stem bark and leaves extracts against $\mathrm{CCl}_{4}$-induced liver damage in rats. Asian Pac J Trop Biomed. 2014;4(6):480-5

32. Huo HZ, Wang B, Liang YK, Bao YY, Gu Y. Hepatoprotective and antioxidant effects of licorice extract against $\mathrm{CCl}_{4}$-induced oxidative damage in rats. Int J Mol Sci. 2011:12(10):6529-43.

33. Janbaz KH, Saeed SA, Gilani AH. Studies on the protective effects of caffeic acid and quercetin on chemical-induced hepatotoxicity in rodents. Phytomedicine. 2004;11(5):424-30.

34. Kus I, Colakoglu N, Pekmez H, Seckin D, Ogeturk M, Sarsilmaz M. Protective effects of caffeic acid phenethyl ester (CAPE) on carbon tetrachlorideinduced hepatotoxicity in rats. Acta Histochem. 2004;106(4):289-97.

35. Gressner OA, Weiskirchen R, Gressner AM. Biomarkers of liver fibrosis: clinical translation of molecular pathogenesis or based on liver-dependent malfunction tests. Clin Chim Acta. 2007:381(2):107-13.

36. Shim JY, Kim MH, Kim HD, Ahn JY, Yun YS, Song JY. Protective action of the immunomodulator ginsan against carbon tetrachloride-induced liver injury via control of oxidative stress and the inflammatory response. Toxicol Appl Pharmacol. 2010:242(3):318-25.

37. Qiao Y, Bai XF, Du YG. Chitosan oligosaccharides protect mice from LPS challenge by attenuation of inflammation and oxidative stress. Int Immunopharmacol. 2011;11(1):121-7. 
38. Quan J, Piao L, Wang X, Li T, Yin X. Rossicaside B protects against carbon tetrachloride-induced hepatotoxicity in mice. Basic Clin Pharmacol Toxicol. 2009;105(6):380-6.

39. Shi Y, Guo L, Shi L, Yu J, Song M, Li Y. Caffeic acid phenethyl ester inhibit hepatic fibrosis by nitric oxide synthase and cystathionine gamma-lyase in rats. Med Sci Monit. 2015;21:2774-80.

40. Lee J, Koo N, Min DB. Reactive oxygen species, aging, and antioxidative nutraceuticals. Compr Rev Food Sci Food Saf. 2004;3(1):21-33.

41. Yin G, Cao L, Xu P, Jeney G, Nakao M, Lu C. Hepatoprotective and antioxidant effects of Glycyrrhiza glabra extract against carbon tetrachloride $\left(\mathrm{CCl}_{4}\right)$-induced hepatocyte damage in common carp (Cyprinus carpio). Fish Physiol Biochem. 2011;37(1):209-16.

42. Reza HM, Sagor MAT, Alam MA. Iron deposition causes oxidative stress, inflammation and fibrosis in carbon tetrachloride-induced liver dysfunction in rats. Bangladesh. Aust J Pharm. 2015:10(1):152-9.

43. Liu C, Tao Q, Sun M, Wu JZ, Yang W, Jian P, et al. Kupffer cells are associated with apoptosis, inflammation and fibrotic effects in hepatic fibrosis in rats. Lab Investig. 2010;90(12):1805-16.

44. Urtasun R, de la Rosa LC, Nieto N. Oxidative and nitrosative stress and fibrogenic response. Clin Liver Dis. 2008;12(4):769-viii.

45. Jang JH, Kang KJ, Kim YH, Kang YN, Lee IS. Reevaluation of experimental model of hepatic fibrosis induced by hepatotoxic drugs: an easy, applicable, and reproducible model. Transplant Proc. 2008;40(8):2700-3.

46. Sebastiani G, Gkouvatsos K, Maffettone C, Busatto G, Guido M, Pantopoulos $\mathrm{K}$. Accelerated $\mathrm{CCl}_{4}$-induced liver fibrosis in $\mathrm{Hjv}-/$ - mice, associated with an oxidative burst and precocious profibrogenic gene expression. PLoS One. 2011;6(9):e25138

47. Canter PH, Thomas H, Ernst E. Bringing medicinal plants into cultivation: opportunities and challenges for biotechnology. Trends Biotechnol. 2005; 23(4):180-5.

48. Aggarwal S, Ichikawa H, Takada Y, Sandur SK, Shishodia S, Aggarwal BB. Curcumin (diferuloylmethane) down-regulates expression of cell proliferation and antiapoptotic and metastatic gene products through suppression of I kappaB alpha kinase and Akt activation. Mol Pharmacol. 2006:69(1):195-206.

49. Itoh A, Isoda K, Kondoh M, Kawase M, Watari A, Kobayashi M, et al. Hepatoprotective effect of syringic acid and vanillic acid on the $\mathrm{CCl}_{4^{-}}$ induced liver injury. Biol Pharm Bull. 2010;33(6):983-7.

50. Rahmatullah M, Khatun MA, Morshed N, Neogi PK, Khan SUA, Hossan MS, et al. A randomized survey of medicinal plants used by folk medicinal healers of Sylhet division, Bangladesh. Adv in Nat. Appl Sci. 2010;4(1):52-62.

51. Uddin N, Hasan MR, Hasan MM, Hossain MM, Alam MR, Hasan MR, et al. Assessment of toxic effects of the methanol extract of Citrus macroptera Montr. Fruit via biochemical and hematological evaluation in female Sprague-Dawley rats. PLoS One. 2014;9(11):e111101.

\section{Submit your manuscript to a SpringerOpen ${ }^{\circ}$ journal and benefit from:}

- Convenient online submission

- Rigorous peer review

- Open access: articles freely available online

- High visibility within the field

Retaining the copyright to your article

Submit your next manuscript at $>$ springeropen.com 